
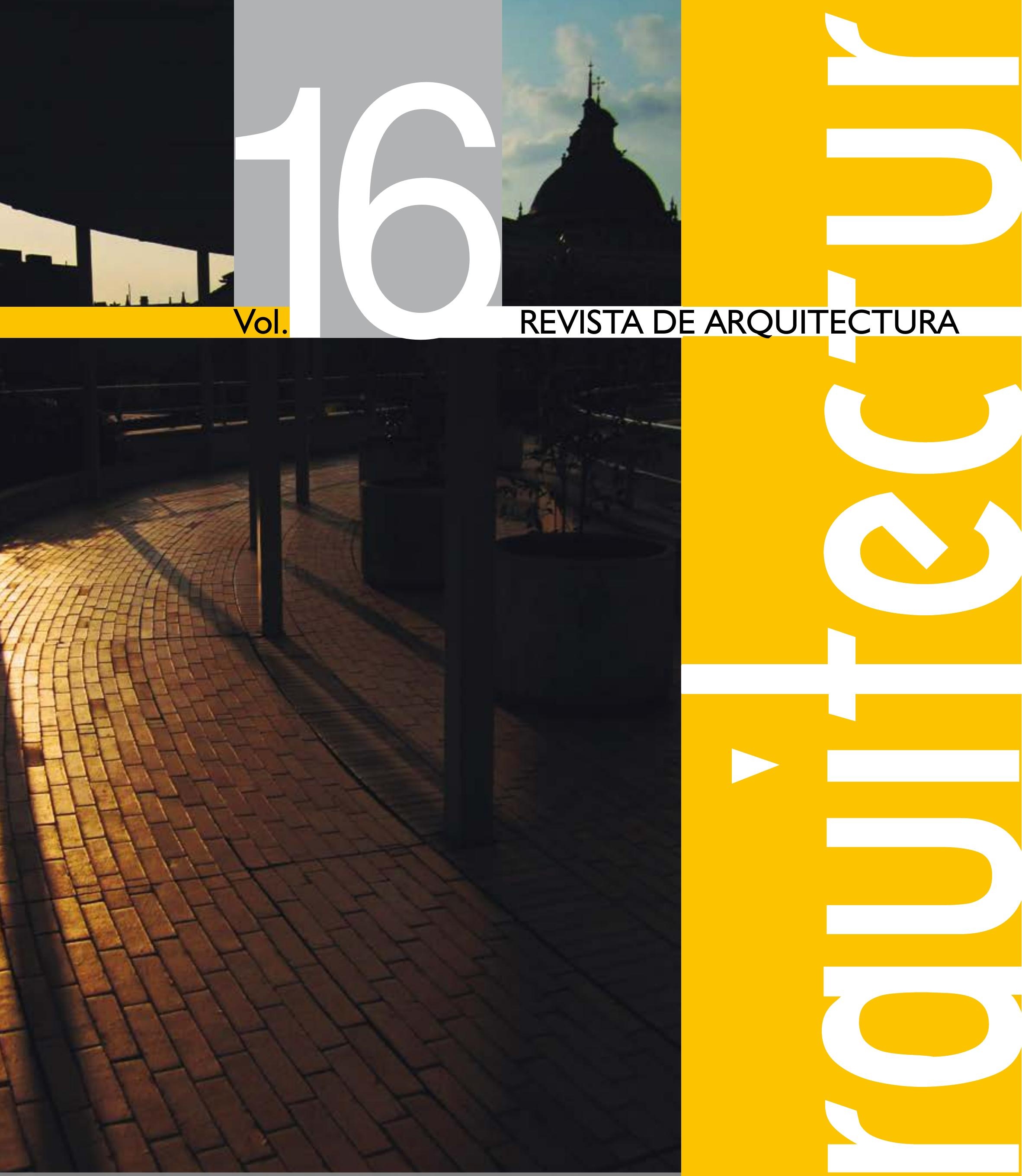
La Revista de Arquitectura (ISSN 16570308 impresa y ISSN 2357626X en línea) es una publicación seriada, arbitrada mediante revisión por pares, indexada y de libre acceso, donde se publican principalmente resultados de investigación originales e inéditos.

Está dirigida a la comunidad académica y profesional de las áreas afines a la disciplina (Arquitectura y Urbanismo). El primer número se publicó en 1999 y continúa con una periodicidad anual (enero-diciembre). Es editada por la Facultad de Diseño y el Centro de Investigaciones de la Facultad de Diseño -CIFAR- de la UNIVERSIDAD CATÓLICA DE COLOMBIA en Bogotá, Colombia.

La revista se estructura en tres secciones correspondientes a las líneas de investigación activas y aprobadas por la institución y una cuarta correspondiente a la dinámica propia de la Facultad de Diseño.

CULTURA Y ESPACIO URBANO. En esta sección se publican los artículos que se refieren a fenómenos sociales en relación con el espacio urbano, atendiendo aspectos de la historia, el patrimonio cultural y físico, y la estructura formal de las ciudades y el territorio.

PROYECTO ARQUITECTÓNICO Y URBANO. En esta sección se presentan artículos sobre el concepto de proyecto, entendido como elemento que define y orienta las condiciones proyectuales que devienen en los hechos arquitectónicos o urbanos, y la forma como estos se convierten en un proceso de investigación y nuevo de conocimiento. También se presentan proyectos que sean resultados de investigación, que se validan a través de la ejecución y transformación en obra construida de proceso investigativo. También se contempla la publicación de investigaciones relacionadas con la pedagogía y didáctica de la arquitectura, el urbanismo y el diseño.

TECNOLOGÍA, MEDIOAMBIENTE Y SOSTENIBILIDAD. En esta sección se presentan artículos acerca de sistemas estructurales, materiales y procesos constructivos, medioambiente y gestión, relacionados con el entorno social-cultural, ecológico y económico.
DESDE LA FACULTAD. En esta sección se publican artículos generados desde el interior de la Facultad de Diseño relacionados con las actividades de docencia, extensión o internacionalización, las cuales son reflejo de la dinámica y de las actividades realizadas por docentes, estudiantes y egresados; esta sección no puede superar el $20 \%$ del contenido con soporte investigativo.

Los objetivos de la Revista de Arquitectura son:

- Promover la investigación, el desarrollo y la difusión del conocimiento generado a nivel local, nacional e internacional.

- Conformar un espacio para la construcción de comunidades académicas y la discusión en torno a las secciones definidas.

- Fomentar la diversidad institucional y geográfica de los autores que participan en la publicación.

- Potenciar la discusión de experiencias e intercambios científicos entre investigadores y profesionales.

- Contribuir a la visión integral de la arquitectura, por medio de la concurrencia y articulación de las secciones mediante la publicación de artículos de calidad.

- Publicar artículos originales e inéditos que han pasado por revisión de pares, para asegurar que se cumplen con las normas de calidad, validez científica y ética editorial e investigativa.

- Fomentar la divulgación de las investigaciones y actividades que se desarrollan en la Facultad de Diseño de la UNIVERSIDAD CATÓLICA DE COLOMBIA.

Palabras clave de la Revista de Arquitectura: Arquitectura, diseño, educación arquitectónica, proyecto y construcción, urbanismo.

Key words for Revista de Arquitectura: Architecture, design, architectural education, urban planning, design-build.

Idiomas de publicación: Español, Inglés, Portugués

Título corto: RevArq
A El editor y los autores son responsables de los artículos aquí publicados.

Los autores son los responsables del material gráfico publicado.

Esta revista se acoge una licencia Creative Commons (CC) de Atribución - No comercial Compartir igual, 4.0 Internacional: "El material creado puede ser distribuido, copiado y exhibido por terceros si se muestra en los créditos. No se puede obtener ningún beneficio comercial y las obras derivadas tienen que estar bajo los mismos términos de licencia que el trabajo original".

Para más información:

http://co.creativecommons.org/tipos-de-licencias/

Universidad Católica de Colombia (2014, enero-diciembre). Revista de Arquitectura, 16. 1-144. ISSN: 1657-0308 E-ISSN 2357626X

(A)

Formato: $34 \times 24 \mathrm{~cm}$

Papel: Mate $115 \mathrm{~g}$

Tintas: Negro y policromía

Periodicidad: Anual
(A) CANje

OBJETIVO:

La Revista de Arquitectura está interesada en establecer canje con publicaciones académicas, profesionales o científicas, del área del Diseño, la Arquitectura y el Urbanismo o la educación superior, como medio de reconocimiento y discusión de la producción científica en el campo de acción de la publicación.

MECANISMO:

Para establecer Canje por favor descargar, diligenciar y enviar al correo electrónico de la Revista el formato:

RevArq FP20 Canjes

\section{A CONTACTO}

DIRECCIÓN POSTAL:

Avenida Caracas № 46 - 72. Universidad Católica de Colombia. Bogotá D.C.- Colombia

Código postal: 111311

Centro de Investigaciones (CIFAR).

Sede El Claustro. Bloque "L", 4 piso, Diag. 46a No. 15b - 10.

Arq. César Andrés Eligio Triana

Teléfonos: + 57 (1) 3277300 - 3277333

Ext. 3109; 3112 ó 5146

Fax: +57 (1) 2858895

CORREO ELECTRÓNICO:

revistadearquitectura@ucatolica.edu.co

cifar@ucatolica.edu.co

PÁGINA WEB:

www.ucatolica.edu.co Vínculo Publicaciones http://portalweb.ucatolica.edu.co/easyWeb2/arquitectura/pages.php/menu/319320363/id/2363/content/ revista-de-arquitectura/

EDITOR:

Mg. en Arq. César Andrés Eligio Triana celigio@ucatolica.edu.co

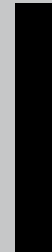


UNIVERSIDAD CATÓLICA DE COLOMBIA

PRESIDENTE

Édgar Gómez Betancourt

VICEPRESIDENTE - RECTOR

Francisco José Gómez Ortiz

VICERRECTOR JURÍDICO Y DEL MEDIO

UNIVERSITARIO

Edwin de Jesús Horta Vásquez

VICERRECTOR ADMINISTRATIVO

Édgar Gómez Ortiz

DECANO ACADÉMICO

Elvers Medellín Lozano

DIRECTORA DE INVESTIGACIONES

Elisa Urbina Sánchez

DIRECTORA EDITORIAL

Stella Valbuena García

\section{FACULTAD DE DISEÑO}

DECANO

Werner Gómez Benítez

DIRECTOR DE DOCENCIA

Jorge Gutiérrez Martínez

DIRECTOR DE EXTENSIÓN

Carlos Beltrán Peinado

DIRECTOR DE INVESTIGACIÓN

Juan Carlos Pérgolis

DIRECTOR DE GESTIÓN DE CALIDAD

Augusto Forero La Rotta

COMITÉ ASESOR EXTERNO

FACULTAD DE DISEÑO

Alberto Miani Uribe

Giovanni Ferroni Del Valle

Samuel Ricardo Vélez

Lorenzo Castro

\section{FACULTAD DE DISEÑO}

\section{Centro de INVESTIGACIONES - CIFAR}

\section{Andultecturo}

\section{REVISTA DE ARQUITECTURA}

DIRECTOR

Werner Gómez Benítez

EDITOR

César Andrés Eligio Triana

CONSEJO EDITORIAL

Werner Gómez Benítez

Jorge Gutiérrez Martínez

César Andrés Eligio Triana

Carlos Beltrán Peinado

Hernando Verdugo Reyes

EQUIPO EDITORIAL

COORDINADORA EDITORIAL

María Paula Godoy Casasbuenas mpgodoy@ucatolica.edu.co

DISEÑO Y MONTAJE

Juanita Isaza

juanaisaza@gmail.com

TRADUCTORA

Diana Carolina Peláez Rodríguez

dc.pelaez@uniandes.edu.co

CORRECTORA DE ESTILO

María José Díaz Granados M. mariajose_dgm@yahoo.com.co

PÁGINA WEB

Centro de investigaciones (CIFAR)

DISTRIBUCIÓN Y CANJES

Claudia Álvarez Duquino

calvarez@ucatolica.edu.co
COMITÉ EDITORIAL

(1)

TESPACIO URBANO

Sonia Berjman, PhD

ICOMOS, Buenos Aires, Argentina

Beatriz García Moreno, PhD

Universidad Nacional de Colombia. Bogotá, Colombia

Juan Carlos Pérgolis, MSc

Universidad Católica de Colombia. Bogotá, Colombia

René Julio Castillo, MSc PhD (Estudios)

Universidad del Rosario. Bogotá, Colombia

Proyecto aRQuitectónico y URbano

Hugo Mondragón López, PhD

Pontificia Universidad Católica de Chile. Santiago, Chile

Juan Pablo Duque Cañas, PhD

Universidad Nacional de Colombia. Bogotá, Colombia

Germán Darío Correal Pachón, MSc.

Universidad Católica de Colombia. Bogotá, Colombia

TECNOLOGÍA, MEDIOAMBIENTE Y SOSTENIBILIDAD

Luis Gabriel Gómez Azpeitia, PhD

Universidad de Colima. Colima, México

Luis Carlos Herrera Sosa, PhD

Universidad Autónoma de Ciudad Juárez, México

COMité CIENTífICO

Jorge Grané del Castillo, MSc Universidad de Costa Rica. San José, Costa Rica

Javier Peinado Pontón, MSc

Pontificia Universidad Javeriana. Bogotá, Colombia

Jorge Alberto Villamizar Hernández Universidad Santo Tomás. Bucaramanga, Colombia

Augusto Forero La Rotta, MSc

Universidad Católica de Colombia. Bogotá, Colombia

Luis Álvaro Flórez Millán, MSc

Universidad Católica de Colombia. Bogotá, Colombia

Elvia Isabel Casas Matiz, MSc

Universidad Católica de Colombia. Bogotá, Colombia 


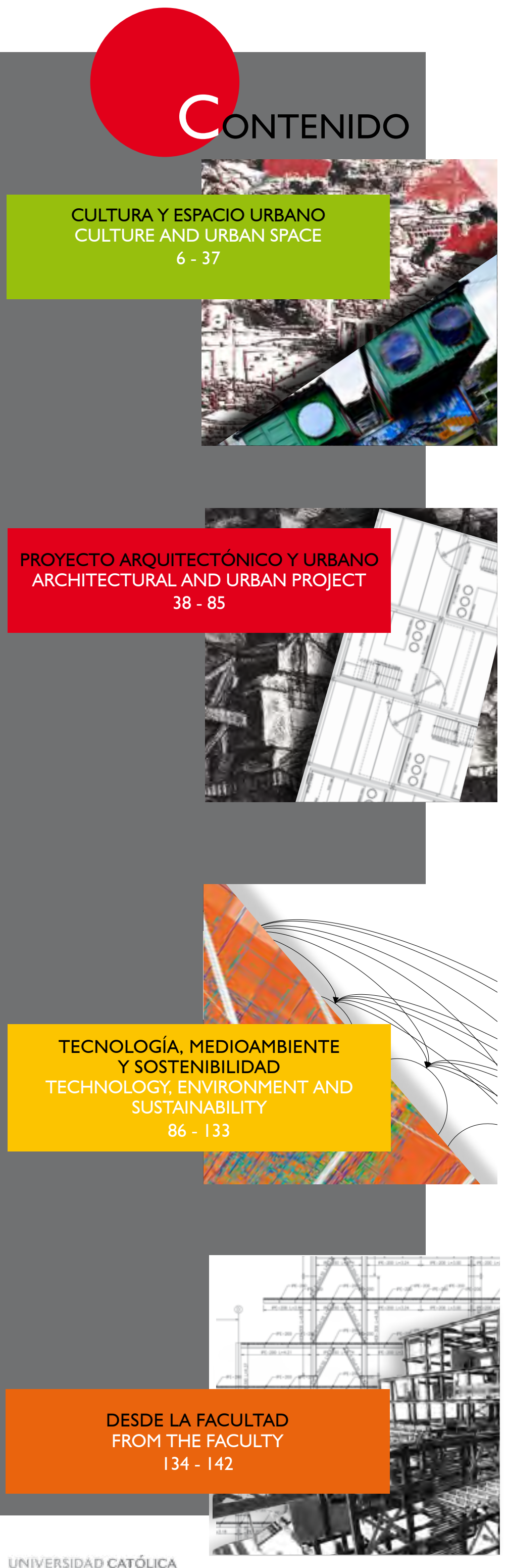

LOS USOS Y LA APROPIACIÓN DEL ESPACIO PÚBLICO PARA EL FORTALECIMIENTO DE LA DEMOCRACIA

PABLO PÁRAMO

ANDREA MILENA BURBANO

CIUDAD Y COMPROMISO CIUDADANO EN

LA HISTORIA DE OCCIDENTE

CARLOS ARTURO OSPINA HERNÁNDEZ

CARACTERIZACIÓN DEL MODELO DE APRENDIZAJE

A PARTIR DE LABORATORIOS DE DISEÑO CON

ÉNFASIS EN FACTORES SOCIALES

Álvaro JaVIER Bolaños Palacios

FABIÁN ADOLFO AgUILERA MARTÍNEZ

ANÁLISIS URBANO Y FORMAL DEL EDIFICIO

MIGUEL DE AGUINAGA

FELIPE VILLA MONTOYA

LEONARDO CORREA VELÁSQUEZ

VIVIENDAS DE EMERGENCIA EN URUGUAY

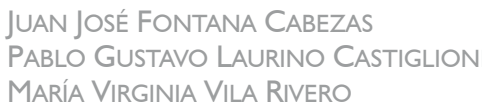

\section{CUESTIONES DE MÉTODO CREATIVO}

METAMORFOSIS Y CONCIENCIA MATERIAL EN LOS PROCESOS

CREATIVOS EN ARQUITECTURA

CARLOS IVÁN RUEDA PLATA

CRÍTICA SISTÉMICA

UN ENFOQUE HERMENÉUTICO DEL FENÓMENO

ARQUITECTÓNICO

ESKA ELENA SOLANO MENESES

TRADUCCIÓN DEL DISEÑO CONCURRENTE AL PROYECTO DE ARQUITECTURA

LUIS ÁLVARO FLóREZ MILLÁN

JaIRO HERnÁn OVAlLE Garay

LEONEL AUGUSTO FORERO LA ROTTA

PÁG. 77

EFICIENCIA DE ESTRATEGIAS DE ENFRIAMIENTO PASIVO EN CLIMA CÁLIDO SECO

LUIS CARLOS HERRERA SOSA

SIMULACIONES AMBIENTALES PARA LA SELECCIÓN DE MATERIALES EN DISEÑO DE ALOJAMIENTOS TEMPORALES EN CLIMAS TROPICALES

SARA LUCIANIM

A INFLUÊNCIA DAS PRATELEIRAS DE LUZ NO APROVEITAMENTO DA LUZ NATURAL SOB OBSTRUÇÃO EXTERNA

RICARDO NACARI MAIOLI

MARIANI DAN TAUFNER

CRISTINA ENGEL DE ALVAREZ

LA HABITABILIDAD COMO VARIABLE DE DISEÑO DE EDIFICACIONES ORIENTADAS A LA SOSTENIBILIDAD

ROLANDO ARTURO CUBILLOS GONZÁLEZ

JOHANNA TRUILLO

OSCAR ALFONSO CORTÉS CELY

Claudia Milena Rodríguez ÁlVAREZ

MAYERLY ROSA VILLAR LOZANO

LA SOSTENIBILIDAD DE LA VIVIENDA TRADICIONAL:

UNA REVISIÓN DEL ESTADO DE LA CUESTIÓN EN EL MUNDO

RIGOBERTO LÁRRAGA LARA

MIGUEL AGUILAR ROBLEDO

HUMBERTO REYES HERNÁNDEZ

JAVIER FORTANELLI MARTÍNEZ

$5^{\circ}$ CONCURSO DE DISEÑO EN ACERO PARA ESTUDIANTES DE ARQUITECTURA EN COLOMBIA - 2014

SEGUNDO PUESTO. MEMORIA

DiEGo AlEjANDRO MORA CASAS

JUAN CAMILO RINCÓN PULIDO

STEVEN GONZÁLEZ ZABALA

LUCAS PARDO MORA 


\title{
TRADUCCIÓN DEL DISEÑO CONCURRENTE AL PROYECTO DE ARQUITECTURA
}

\author{
Luis Álvaro Flórez Millán, Jairo Hernán Ovalle Garay, Leonel Augusto Forero La Rotta \\ Universidad Católica de Colombia, Bogotá (Colombia) \\ Facultad de Diseño, Grupo de Investigación Cultura, Espacio y Medioambiente Urbano (CEMA)
}

Flórez Millán, L A., Ovalle Garay, J. H. y Forero La Rotta, L. A. (2014). Traducción del diseno concurrente al proyecto de arquitectura. Revista de Arquitectura, 16, 77-85. doi: 10.14718/RevArq.2014.16.9

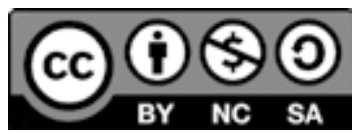

http://dx.doi.org/10.14718/ RevArq.2014.16.9

\section{Luis Alvaro Flórez Millán}

Arquitecto, Universidad Católica de Colombia.

Maestría en Diseño Industrial, Escuela de Diseño y Arquitectura de América Latina y el Caribe (ISTHMUS).

Maestría en Historia, Universidad Pedagógica y Tecnológica de Tunja (UPTC).

Coordinador Núcleo Problémico 2 Lugar. Profesor de Diseño Arquitectónico, Universidad Católica de Colombia. laflorez@ucatolica.edu.co

\section{Jairo Hernán Ovalle Garay}

Arquitecto, Universidad Nacional de Colombia, sede Manizales.

Maestría en Arquitectura, Universidad Nacional de Colombia.

Director del Grupo de Investigación Proyectual en Arquitectura PROARQ, Universidad Católica de Colombia.

Profesor de Diseño Urbano y Arquitectónico, Universidad Católica de Colombia.

jhovalle@ucatolica.edu.co

Leonel Augusto Forero La Rotta

Arquitecto, Fundación Universidad de América.

Maestría en Diseño Industrial, Escuela de Diseño y Arquitectura de América Latina y el Caribe (ISTHMUS).

Maestría en Historia, Universidad Pedagógica y Tecnológica de Tunja (UPTC).

Director de Gestión y Calidad, Facultad de Diseño, Universidad

Católica de Colombia.

laforero@ucatolica.edu.co

\section{RESUMEN}

La ingeniería concurrente viene de la exploración de procesos industriales, y busca mejorar el rendimiento y la eficiencia en la fabricación de objetos. El diseño concurrente transforma este proceso, produciendo ideas generadoras y multidisciplinares que giran de forma simultánea en torno a un proyecto. Este artículo presenta la conceptualización en torno al diseño concurrente desde lo metodológico y procedimental, y busca brindar herramientas para optimizar el desarrollo y la articulación del conocimiento asumiendo el papel de traductor de los procesos tomados de la ingeniería concurrente aplicándolos al proyecto arquitectónico. Para esto, el texto se dividió en tres partes. La primera recopila algunas definiciones concernientes a diseño y concurrencia. Posteriormente, estos conceptos son integrados en la construcción de una definición propia, que sirve de marco para la tercera parte donde se aplican, tomando como campo de exploración el Programa de Arquitectura de la Facultad de Diseño de la Universidad Católica de Colombia.

PALABRAS CLAVE: conocimiento, formación profesional, aprendizaje, multidisciplinariedad, enseñanza, metodologías de aprendizaje.

TRANSIATION OF THE CONCURRENT DESIGN TO THE ARCHITECTURE PROJECT

\section{ABSTRACT}

Concurrent engeneering comes from the exploration of industrial processes and it seeks to improve the performance and efficiency of object manufacturing. Concurrent design transforms this process, producing creative and multidisciplinary ideas that simultaneously hinge upon a project. This article presents the conceptualization set around concurrent design from a methodologic and procedural point of view, and it seeks to provide some tools to optimize knowledge development and articulation, asuming the role of the translator of processes taken from concurrent engeneering applied to architecture projects. To this end, the text is divided in three parts. The first one compiles some definitions regarding design and concurrence. Subsequently, these concepts are integrated in the construction of a definition of our own, that serves as a framework for the third part where they are applied; having as the exploration field the School of Architecture of Universidad Catolica de Colombia Faculty of Design.

KEY WORDS: Knowledge, professional education, learning, multidisciplinarity, tuition, learning methodologies.

\section{INTRODUCCIÓN}

El presente texto hace parte de la investigación "Diseño concurrente en el proyecto de arquitectura", desarrollada en el Centro de Investigaciones de la Facultad de Diseño (CIFAR) en la Universidad Católica de Colombia. El interrogante inicial planteado: ¿Cómo se desarrolla el diseño concurrente como estrategia de diseño en arquitectura?, tiene como premisa que este diseño, aplicado como un método de aprendizaje, requiere de una clarificación y conceptualización, con el fin de establecer los parámetros sobre los que cada uno de los actores implicados comprenda cuál es su papel en el desarrollo del proyecto, como herramienta de aprendizaje y articulación del conocimiento.

Esta investigación pretende establecer un marco conceptual sobre el cual construir la idea de un diseño concurrente que permita la aplicación al proyecto de arquitectura, como herramienta operacional y pieza clave de articulación y coordinación entre los diferentes campos del saber.

Así planteado, el diseño concurrente como alternativa de optimización de procesos de producción con énfasis en el diseño industrial y textil, es llevado al aula como metodología, y permite revisar los procesos que actualmente hacen parte del aprendizaje. Adicional a esto, aunque las fuentes consultadas no hablan directamente acerca de un proceso concurrente en el proyecto de arquitectura, los temas relacionados con procesos, rendimientos y eficiencia en la fabricación de objetos e ideas, requieren de una adaptación de la ingeniería concurrente a la terminología del diseño concurrente aplicados a la arquitectura. Asimismo, es necesario pensar conceptualmente desde las metodologías y los procedimientos, y brindar herramientas sobre cómo integrarlos a la formación de los programas de arquitectura, donde el proyecto es el mediador que permite la traducción de los procesos de ingeniería "como una forma de conocimiento y realización práctica" (Correal, 2007, p. 49) ${ }^{1}$ concentrados ahora más en los sujetos que en los objetos.

1 Esta definición otorga al proyecto la capacidad de constructor de conocimiento, consecuente con la labor académica de la escuela (Correal, 2007). 


\section{Metodología}

Al ser este el producto de un trabajo de investigación científica de carácter exploratorio, la metodología propuesta parte de la necesidad de construir un estado del arte que permita la revisión del concepto de diseño y las implicaciones ante la actividad concurrente para encontrar su aplicación en la arquitectura. Para esto, el trabajo se divide en tres partes: en la primera, toma los conceptos de diseño y concurrencia de forma separada, con el fin de establecer con las evidencias documentales disponibles en fuentes secundarias los primeros indicios encontrados en el diseño y la ingeniería industrial, conocidos también como ingeniería concurrente. Esta búsqueda particular de cada uno de los términos, tiene un especial interés en la concurrencia, donde el vocabulario tradicional hace referencia a la articulación o reunión de actividades y personas con el ánimo de logar un objetivo en común.

El diseño ligado a la palabra "concurrente", adquiere un valor más profundo, en especial en el desarrollo de los procesos y métodos que faciliten el logro de los objetivos propuestos, mejorando la calidad de los productos desde lo formal, optimizando los tiempos de producción, así como el desarrollo y la inversión de recursos.

En la segunda parte, se toma como campo de exploración el modelo de concurrencias basado en el taller de Diseño Arquitectónico propuesto en la Facultad de Diseño de la Universidad Católica de Colombia, como punto de reunión y articulación de los temas relacionados con la arquitectura, la ciudad y la construcción; también se exploran los documentos utilizados en la conceptualización teórica y la representación del proyecto. Dicha actividad se llevó a cabo mediante visitas a los cortes parciales y entregas finales, tomando registro fotográfico de las entregas, y dialogando con los estudiantes y profesores acerca de los resultados colectivos frente a las metodologías aplicadas. Finalmente, en la tercera parte, y con base en la documentación inicial y en la revisión empírica posterior, el texto se ocupa de la conexión del diseño concurrente con el proyecto de arquitectura, entendido este como una actividad o una "manera de hacer arquitectura de proyección donde esta lógica es en realidad el oficio" (Rossi, 1977), y determinar de forma constructiva, las posibles dificultades que se presentaron a lo largo del proceso.

\section{RESULTADOS}

\section{DEL DISEÑO LINEAL AL DISEÑO CONCURRENTE}

El diseño lineal, también conocido como secuencial o escalonado, es aquel en el que el proceso de diseño se desarrolla a partir de eta- pas sucesivas, por tanto, una etapa del proceso no se puede iniciar sin concluir la anterior, con las consecuentes esperas y pérdidas de tiempo. El diseño integrativo, también conocido como concurrente, es definido como "un recorrido no lineal en un constante re-hacer el camino con el otro, debido en primera instancia a que el contexto está en una continua renovación" (Correal, 2010, p. 15).

Según Correal, citando a V. Gregotti, en este diseño integrativo nos adentramos en una "conversación proyectual" (Correal, 2010, p. 54) fundamentada en un producto intelectual y sensible. Esta conversación interdisciplinar permite construir el conocimiento proyectual de "manera recursiva" (Maturana, 1995, p. 97), en dos niveles: el discursivo y el gráfico y representativo. La interdisciplina, como un esfuerzo de síntesis, es "el lugar geométrico donde se despliega la investigación, la teoría y la práctica que parte de unos problemas para proponer nuevos problemas" (Rodríguez, 1998, pp. 30-31).

El desarrollo del proyecto, según Correal, requiere de un pensar y proyectar en una constante "prueba y error" (2010, pp. 22, 85) como método proyectual, en una continua indagación e interrogación, en un pensamiento en simultáneo en la búsqueda de los "momentos o instancias proyectuales" (pp. 25-28) que surgen del aprendizaje a partir de la construcción recurrente de un mapeo que conlleva implícito un discurso espacial, formal y técnico. Esta búsqueda en la producción del proyecto implica: "caminos que se separan y se unen, representaciones dispares, codificaciones diferentes, diversidad de visualizaciones mentales, distintos modos de lectura y diversas reconstrucciones por el lenguaje, estas manifestaciones del conocimiento no ocurren en un solo sentido, su estado es realmente el multidireccional" (pp. 70-76).

\section{Construcción de un concepto}

\section{- Diseño}

El diseño es una metodología proyectual compleja que busca dar una respuesta formal a las preguntas que nos surgen sobre las condiciones espaciales requeridas para que el hombre realice efectivamente una diversidad de actividades sobre un territorio en condiciones ambientales específicas. Como proceso intelectual, se traduce en la práctica proyectual donde se ponen en escena los conceptos y los requerimientos que de forma abstracta se disponen para la construcción de la estructura mental.

En el caso del proyecto arquitectónico, el estudio de la implantación en un contexto determinado, permite la argumentación de los fenómenos que se entrecruzan simultáneamente en los ciclos de análisis y diagnóstico, 
y de estrategias de intervención, construyendo criterios de distinto orden, al entorno urbano o natural existente. Una vez incorporado el valor de lo fenoménico fundamentado en el análisis de las prácticas culturales, se procede al desarrollo de un modelo con la aplicación de elementos de un orden superior, como son la estructura y la infraestructura, que se convierten en la manifestación más pura del pensamiento complejo sobre lo material real hasta lograr valores más avanzados como el de la gestión en etapas superiores.

En resumen, el diseño es un proceso que se organiza a partir de la concepción de una estructura mental que nos permite plantear de manera ordenada los problemas, con plena comprensión de los contextos, las condiciones, los requerimientos y todas aquellas pautas que orientan y dan sentido a las posibles soluciones concebidas de manera integrada en todos los aspectos del ciclo de vida del objeto arquitectónico, y como expresión y significado de una cultura cuyo resultado es un discurso formal de nuevo conocimiento.

\section{- Concurrente}

La concurrencia, como problema epistemológico y filosófico, se fundamenta en la generación de diversas lecturas en simultáneo en un constante devenir. Para actuar en concurrencia, se requiere que los participantes propongan un escenario de pensamiento integrativo + sustractivo, es decir, el planteamiento de nuevas situaciones diversas abstraídas. Se trata de conocer las definiciones sobre el concepto de concurrencia, donde algunas de las expresiones más tradicionales en la historiografía resultan apropiadas a las situaciones o los escenarios que se puedan presentar en el desarrollo de los proyectos.

A principios del siglo XV aparece en España el concepto "concurrir", que tomado del latín concǔrrěre significa "correr junto con otros", "lanzar el trompo", "especie de camino", "dejar correr el agua", "camino hecho por mar", "correr acá y acullá", "tratar de algo", "curso de las aguas", "echar uno de sí", "ahuyentar, librar de" y "correr afuera" (Corominas, 1996, pp. 208-211). La concurrencia es la acción de concurrir o reunirse varias circunstancias, sucesos, etc., o conjunto de personas "presentes en" o el concurso en el sentido de asistencia, asistentes y "entrada para" o "por", la ayuda, la cooperación y el influjo. La palabra concurrente se aplica a lo que concurre a algún sitio o algo (Moliner, 1982, p. 711). Concurrente es juntarse en un mismo lugar o tiempo, coincidir en algo o en alguien, y contribuir con una cantidad para determinado fin, convenir en una opinión y concursar o "tomar parte de" (RAE, 2001).
Concurrente también se encuentra en: "parece que el bien y el mal distan tan poco el uno del otro que son como dos líneas concurrentes, que aunque parten de apartados y diferentes principios, acaban en un punto (Enciclopedia Universal Ilustrada, 1933, pp. 333-336). Acaecimiento simultáneo de cosas, concurso de diversos sucesos en un mismo tiempo, sobrevenida, acontecimiento impensado a la par de otro o entre otros que se esperaban, etc. Ayuda, auxilio cooperación, compañía, tertulia, sociedad, círculo, competencia y acción simultánea de dos o más (Cuervo, 1994, p. 1010).

Concurrencia es la competencia que se establece entre los individuos o entre los grupos sociales que aspiran a obtener las mismas ventajas en un asunto y se esfuerzan por conseguirlas (Cuervo, 1994, p. 1010). También es: convenir con otro $u$ otros en el mismo dictamen o pretender al mismo tiempo un mismo destino ( $p$. 1013). Concurrence significa, simultáneamente, congregación y "un punto de intersección" (Simons and Schuster, 1973).

En resumen, concurrente es la construcción de un discurso que nos permite transferir simultaneidad de conocimientos desde los distintos saberes que apoyan la definición de los criterios por trabajar, hacia la generación de las ideas del proyecto. El discurso se construye por medio de un camino metodológico que traza una ruta hacia el objetivo central que es la resolución del proyecto.

\section{Lo que se conoce como diseño concurrente}

En los estudios de Arango, Serna y Gómez (2012, pp. 127-137), Luna (1999, p. 81), Luna y Mendoza B. (2004, p. 60), Carretero, Contero, Valiente y Gómis (2002, p. 1), García (2004, p. 40), Quiroga y Hernández (2009, p. 122), Londoño (1994, p. 8), entre otros, se hace referencia al concepto de diseño concurrente desde la ingeniería concurrente, citando a R. I. Winner, J. P. Pennell, H. E. Bertend, M. M. G. Slusarczuk, con el reporte IDA Report R-388 que dice:

\footnotetext{
La ingeniería concurrente es una aproximación al diseño concurrente integrado de productos y a sus procesos relacionados, incluyendo fabricación y soporte. Esta aproximación pretende que quienes desarrollan el producto consideren todos los elementos del ciclo de vida del producto desde su concepción hasta su reciclaje, incluyendo calidad, costo, tiempo y necesidades del usuario (Winner, Pennell, Bertrand y Slusarczuk, 1988, p. 11).
}

En esta definición, el diseño concurrente aparece como un proceso en simultáneo de todas las etapas implícitas en la fabricación de un producto, apartándose de la definición de diseño lineal. 
La primera definición encontrada especifica que:

... el diseño concurrente es una metodología de diseño que conecta de forma simultánea todas las etapas del ciclo de vida de un producto o proyecto, donde el equipo de diseño trabaja de manera sincronizada e integrada para reducir tiempos y costos, en especial en la repetición de procesos, durante el diseño hasta el desarrollo del producto, con especial interés en la etapa inicial en donde se pueden realizar todos los ajustes y cambios del diseño, hasta su terminación y/o reciclaje (Universidad Católica de Chile, 2002, p. 13).

Es una metodología de interconexión entre las partes, donde la integración y la sincronización soportan el trabajo en equipo del diseño.

$\mathrm{Y}$ aunque no se encuentran documentos que traten específicamente el tema del diseño concurrente aplicado al proyecto de arquitectura, es la industria de la construcción donde:

el diseño concurrente se ha utilizado en proyectos de ingeniería civil para el diseño de soluciones constructivas innovadoras donde con equilibrio compiten las limitaciones derivadas del presupuesto ambiental y los requisitos de sostenibilidad. Este modelo, permite desarrollar y establecer una fórmula de trabajo colaborativo desde la fase inicial de diseño, teniendo en cuenta el ciclo de vida completo de un edificio (RHEA, 2013, p. 4).

En términos de la ingeniería concurrente, RHEA ${ }^{2}$ propone que "el diseño concurrente es la aproximación integrada y multidisciplinaria al

2 RHEA (antes conocido como Centro de Educación Espacial $E P F L)$, es una empresa de ingeniería espacial, consultoría y software, que ofrece servicios basados en el conocimiento y soluciones innovadoras para la industria espacial. Para ver más, consultar: http://www.rheagroup.com/\#sthash.elY8aSrF. dpuf diseño e ingeniería que integra las restricciones tecnológicas, costos, riesgos y la planeación de proyectos complejos durante las primeras etapas conceptuales y de factibilidad" (2011, p. 1).

La definición de T. Broughton de Rolls Royce, citado por Escorsa, propone:

La ingeniería simultánea es un intento de optimizar el diseño del producto y el proceso de fabricación, con el objeto de reducir el tiempo de respuesta, mejorar la calidad y bajar el coste mediante la integración de las actividades de diseño y producción, maximizando las actividades en paralelo que ejecutan ambas funciones desde el inicio del desarrollo del producto (Escorsa y Valls, 2005, p. 182).

Para Escorsa, es importante establecer la acción de transformación que se convierte en la base de la ingeniería simultánea y la concibe como "una propuesta que cambia la conexión o enlace entre las fases por la conformación de un equipo multidisciplinar que desarrolla el producto en una interacción constante desde el inicio hasta el final" (Escorsa y Valls, 2005, p. 182). El autor define este interactuar como una "superposición" de actividad permanente.

Por esto la importancia de lograr "una traducción del diseño concurrente al proyecto de arquitectura", porque se trata de un proceso de adaptación de metodologías que proceden de otras disciplinas, donde "el diseño integrado es la clave" (Winner et al., 1988, p. 11). A continuación, en la figura 1 se enumeran algunos de los aspectos más importantes que se encuentran descritos en la gran mayoría de definiciones de los autores consultados, y que se consideran como importantes para la concepción del diseño concurrente:

\section{$\rightarrow$ Figura 1. Aspectos relevantes en las} definiciones de autores sobre diseño concurrente Fuente: los autores.

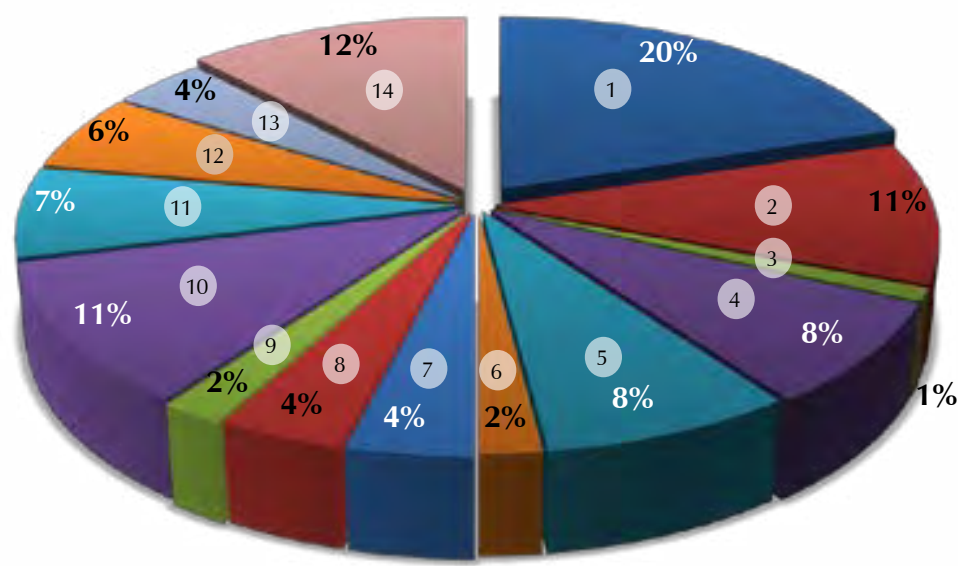

1 Enfoque de diseño integrado - Asociado - Estratégico

2 Creacion de un grupo interdisciplinario

3 Condiciones estructurales: funcionales, fabricacion y mantenimiento

4 Evitar los ciclos repetitivos (tener en cuenta todo)

5 Reduccion de tiempo de entrega - Acortar los tiempos

6 Competitividad

7 Elevar la productividad - Prestaciones del producto - Aumentar la flexibilidad

8 Tecnologías de la información y la comunicación - BIM

9 Cadena de valor

10 Ciclo de vida

11 Diseño conceptual hasta su disponibilidad

12 Necesidades de los usuarios - Satisfacción del cliente

13 Eficiencia - Optimización de los recursos

14 Elevar la calidad, bajo costo 
Los aspectos relacionados en la figura 1 , son considerados en distintos grados de importancia por los diferentes estudios en las concepciones del diseño concurrente: el porcentaje más alto de las definiciones busca la transformación de las jerarquías tradicionales por la innovación fruto del trabajo de un equipo coordinado y sincronizado que, mediante un enfoque horizontal de diseño integrado, asociado y estratégico, emprenda sus prácticas en simultáneo. En un siguiente nivel están las definiciones que mencionan la importancia de aumentar la calidad del producto y la reducción de los costos.
Otro porcentaje de las opiniones menciona la importancia del trabajo de un equipo interdisciplinario o "práctica integrada" (Mayne, 2005), centrada en el ciclo de vida del producto. Este proceso requiere del acopio simultáneo de toda la información desde las primeras fases de diseño, y con ella se planean todos los aspectos de la cadena de valor del producto. Ya en otro nivel de importancia, algunos actores se muestran a favor de una buena estructura del proceso que evite la duplicidad de las actividades y así reducir los tiempos de entrega final de un producto a satisfacción del usuario (figura 2).
Figura 2. Diseño concurrente en la industria Fuente: los autores.

DISEÑO
CONCURRENTE
(Carlos Riba)

TRES PARTES

1. Nueva dimensión del diseño

2. Estructuración del diseño

3. Herramientas para el diseño :
- Ingeniería concurrente, Ciclo de vida, Gama de producto - Ciclos de diseño, Procesos de desarrollo

- Materialización de la solución, Documentar la fabricación

$$
\begin{aligned}
& \text { - Diseño para la fabricación } \\
& \text { - Diseño para el montaje } \\
& \text { - Diseño para la calidad } \\
& \text { - Diseño para el entorno }
\end{aligned}
$$

\section{ORIENTADO A LA PRODUCCIÓN}

- Importancia de las etapas de diseño y desarrollo (especificación y diseño conceptual)

- Contexto empresarial

- Incorporar en estas etapas condicionantes y requerimientos de otros contextos

- Entorno productivo (fabricación, montaje, calidad, transporte)

- Entorno utilización (funciones, prestaciones, fiabilidad, mantenimiento)

- Entorno social (ergonomía, seguridad, impactos ambientales, fin de vida)

> REVISIÓN A LA FORMA DE HACER UN PRODUCTO, DESDE SU CONCEPCIÓN HASTA LOS PROCESOS DE:

- Diseñar para la fabricación y el montaje en la producción

- Diseño para una fácil ejecución

CONCEPTOS - Relacionados con la ingeniería concurrente

1. INGENIERÍA SIMULTÁNEA.

2. DISEÑO PARA LA CALIDAD

3. DISEÑO PARA EL ENTORNO - FACTOR HUMANO

4. DISEÑO PARA EL CONTEXTO DE LA GAMA DE PRODUCTO

5. EQUIPOS PLURIDISCIPLINARIOS

6. GESTOR DE PROYECTO

7. ÉNFASIS EN LA DEFINICIÓN DEL PRODUCTO Y EN EL DISEÑO CONCEPTUAL

8. ESTRUCTURA MODULAR Y SUBPROYECTOS

9. HERRAMIENTAS BASADAS EN LA INFORMÁTICA

10.PROTOTIPOS Y ÚTILES RÁPIDOS

\section{ORIENTACIONES DE LA INGENIERÍA CONCURRENTE}

- AL PRODUCTO - Proceso de fabricación

- AL ENTORNO - La utilidad

\section{HERRAMIENTTAS PARA EL DISEÑO CONCURRENTE}

1. Modularidad y complejidad de un producto

- Módulos funcionales

- Módulos constructivos

2. Diseño para la fabricación

- Conformación de piezas - Diseño para la conformación

- Montaje de producto - Diseño para el montaje

3. Diseño para el montaje

4. Diseño para la calidad

5. Diseño para el entorno 


\section{DISEÑO CONCURRENTE EN EL PROYECTO DE ARQUITECTURA}

Como se mencionó en la primera parte del artículo, el concepto de diseño concurrente es el resultado de la unión de dos términos, por un lado está la disciplina del diseño y, por el otro, como forma gramatical, el participio activo del verbo concurrir (RAE, 2001), que es concurrente o que sucederá simultáneamente, y que significa práctica proyectual jerárquica, concebida a partir del conocimiento técnico aplicado por profesionales de los distintos saberes, en una continua superposición de fundamentos y métodos para la resolución de los problemas que permiten el logro de autonomía, integralidad, innovación, interdisciplinariedad y flexibilidad.

El diseño concurrente en arquitectura pasa necesariamente por un proceso de adaptación, al ser una práctica recurrente en otras disciplinas como la ingeniería, en donde se presenta como ingeniería concurrente, o el diseño industrial. Pero, entonces, ¿cómo se aplica el diseño concurrente en el proyecto de arquitectura? y, ¿cómo construir una herramienta conceptual y operativa en el diseño concurrente?

En el camino de construcción del concepto, el diseño es entendido como "un fenómeno universal que crea tradiciones con funciones simbólicas y que obtiene su significado del contexto en el que se desarrolla y de todas sus posibles formas de aplicación. Al referirse al diseño se alude por tanto a algo abstracto y genérico" (Forero y Flórez, 2005, p. 29). Pero, iqué es lo que hace que la concurrencia sea una alternativa de desarrollo del proyecto en arquitectura? ¿Cuáles son sus formas de control y sus escenarios de actuación? ¿Qué medios utiliza? En arquitectura, es la práctica proyectual la que orienta las propuestas y los proyectos de manera que se produzcan soluciones arquitectónicas colaborativas que favorezcan la calidad de vida de las personas y permitan afrontar los retos contemporáneos y futuros de la disciplina, así como el aprendizaje metodológico del trabajo en equipo con un enfoque pedagógico orientado hacia la indagación y conectado con la realidad económica y productiva del contexto.

- Lo que se hace

Esta forma de afrontar el proyecto requiere de una coordinación que se encarga de la organización de los aspectos más generales del proyecto y de la invitación al equipo interdisciplinar, con una "asignación de tareas específicas y unas restricciones prioritarias en la gestión de proyectos en los términos de plazo y precedencias" (Badr, 1993, p. 1); además, "en un trabajo en equipo debe existir respeto entre los miembros del equi- po, integración, cordialidad, compañerismo, comunicación fluida y objetivos comunes para todos" (Barba, 2000, pp. 9-15).

- El control

Para el control de los procesos de avance y desarrollo de los proyectos en el diseño concurrente, se sigue el ejemplo de Badr: primero, el "control y manejo de los componentes del sistema y segundo el control y la coordinación de las interacciones entre los miembros del equipo de trabajo" (Badr, 1993, p. 1).

Para el segundo control, se designa un líder del equipo de pares que es el responsable del control del proceso de diseño, que depende de la óptima ejecución del diseño concurrente, en el cual se facilite "la creación de un diseño del producto al mismo tiempo porque considera todos los elementos del ciclo de vida del producto desde la concepción hasta su reciclaje" (Jiang, 2000, p. 2); el conocimiento aplicado en la práctica proyectual busca una mayor "agilidad en la generación de las ideas" del proyecto (Barba, 2000, pp. 9-15), para un mejor desarrollo, que surge de los encuentros simultáneos y periódicos entre los miembros del equipo y que permite que "en las etapas tempranas del diseño emerjan las decisiones importantes alrededor del todo, en lugar de sus partes individualizadas" (Jiang, 2000, p. 2).

Este control busca superar las dificultades que se presentan en el proceso de diseño: primero, por las posibles divergencias que puedan surgir "cuando los actores del diseño se encuentran alejados el uno del otro y aplican criterios de diseño diferentes" (Jiang, 2000, p. 2). Por esto, la comunicación permanente del equipo sobre el desarrollo del diseño permite que se incrementen las dinámicas para la resolución de desacuerdos y conflictos, y conformar una "comunidad de comunicación fluida" (Universidad Católica de Colombia, 2010, p. 13). La segunda dificultad que se puede producir es la "duplicidad de actividades en el sistema que afecta el rendimiento del proceso y factor crítico en la fase de diseño de producto" (Jiang, 2000, 2), y para ello el encuentro rutinario permite visualizar anticipadamente los futuros problemas del diseño y así acortar los tiempos de desarrollo del objeto.

\section{- El escenario}

El escenario escogido para la verificación de cómo se podría llevar a cabo esta metodología en el proyecto de arquitectura, fue el aula de clase como espacio de conversación, regido por un principio activo de integración y de compromiso entre docentes que "comunican su experiencia, conocimiento, prioridades y criterios a todos los 
otros miembros del equipo" (Jiang, 2000, p. 2 ), en un proceso de aprendizaje colaborativo y favorable a la creación de una comunidad de estudio sobre la arquitectura, que establece acciones de cooperación donde "se espera el esfuerzo de todos los miembros involucrados en el diseño para participar en la discusión y negociación de las diferencias conceptuales y discursivas encontradas" (p. 2).

- Los medios

Los medios de los que se vale el diseño concurrente se fundamentan en el desarrollo de las capacidades del profesional para dominar un conjunto de tareas específicas de la disciplina de la arquitectura, tales como, la capacidad de identificar los distintos niveles de intervención del proyecto y la capacidad para definir técnicamente procesos constructivos y materiales de acuerdo con las necesidades del proyecto (Universidad Católica de Colombia, 2010, pp. 14-17). El espacio para el desarrollo de estas capacidades es el taller de arquitectura, del que se obtiene un producto mediante una acción interdisciplinar que se construye en conjunto, y que se basa en el hacer en grupo y como resultado de la colaboración multidisciplinar.

Actualmente, las nuevas prácticas de concurrencia exigen una interrelación de los actores del proceso con la utilización de las herramientas BIM o modelado en condiciones paramétricas de diseño, "de forma que se puedan realizar con prontitud los cambios durante la ejecución del plan con el uso de las tecnologías de la información y la comunicación para la toma de decisiones, para la planificación y coordinación del equipo de diseño" (Badr, 1993, p. 13).

Desde la perspectiva de los expertos que participan en los equipos de trabajo, la interdisciplina se considera como el soporte disciplinar estratégico y el territorio propicio para el trabajo del diseño concurrente, porque propone:

... tres momentos: primero el estudio de los fenómenos en los que la arquitectura debe propiciar la calidad de vida del ser humano; segundo, la interpretación de los fenómenos utilizando los elementos del lenguaje de la arquitectura y el último es el planteamiento de la situación problémica que permite la integración de las teorías, los métodos y los conceptos provenientes de los distintos campos del conocimiento disciplinar (Rodríguez, 1998, p. 19).

\section{- El producto}

El producto esperado por el modelo de diseño concurrente, y resultado de toda esta acción interdisciplinar, es el proyecto de arqui- tectura. Se trata de una unidad estratégica y completa, en una interacción compleja en múltiples escalas y dentro de un proceso de análisis, síntesis y simplificación. Dentro del esquema de diseño concurrente, las distintas escalas deben ser manejadas por el equipo de diseño de manera simultánea, para ello estos "enfoques concurrentes permiten explorar el problema sobre el cual se sabe poco desde la escala más pequeña hasta una escala mayor y descubrir nuevos fenómenos" (Lu y Kaxiras, 2004, p. 8) (figura 3).

\section{BúSOUEDAS EN EL TALLER DE DISEÑO}

A partir de la hipótesis planteada, la búsqueda del problema del proyecto, así como de un instrumento articulador de información, hacen parte del proceso del "quehacer" del diseño arquitectónico, donde los interrogantes planteados siguen una secuencia que considera los aspectos centrales del manejo del espacio en sus diversas escalas dentro de la práctica profesional desarrollada tanto en las oficinas como en las escuelas de arquitectura.

Con base en las entrevistas y conversaciones realizadas con docentes y estudiantes en el espacio del taller como campo de experimentación, se puede decir que de los diez niveles de interacción analizados entre el diseño arquitectónico con problemas como la relación con el contexto, la representación, la materialidad o la sustentación teórica, existe un elevado nivel de interacción entre diseño arquitectónico y representación, influenciado además por la importancia que ha adquirido en el tiempo por la responsabilidad asignada de liderazgo ante las demás actividades. Caso contrario ocurre frente a aspectos urbanos y constructivos debido a la falta de comunicación disciplinar en el desarrollo del proyecto.

Según lo anterior, se requiere de una interconexión equilibrada de todos los aspectos en beneficio de planteamientos conceptuales más serios y responsables, e involucrados en el campo de las nuevas metodologías aplicadas a la resolución de preguntas, lo que implica la interacción exitosa de los conductores de los grupos interdisciplinarios, así como la utilización de nuevos programas y la ayuda de software especializado para el desarrollo total del proyecto que de alguna manera le permita a los actores descubrir nuevas respuestas a las preguntas planteadas.

Este trabajo de diseño concurrente nos permitirá obtener un mayor desarrollo de los proyectos al detalle, cuantificados, sujetos a todos los estándares necesarios y cumpliendo con la 


DISEÑO
INTEGRATIVO
DISEÑO
CONCURRENTEN EN
$\begin{aligned} & \text { ARQUITECTURA } \\ & \text { (Investigación) }\end{aligned}$

1. Compromisos académicos en la Facultad

2. Abrir el estudio a otras opciones - Maestría

3. ¿Qué otros caminos es posible tomar?

PENSAMIENTO INTEGRATIVO

1. Sentido-Fortalecimiento del pregrado

2. Investigación de respaldo: basada en bibliografía, cortes de diseño arquitectónico, métodos aplicativos particulares.

MUESTREO
1. Saber qué se hace en la Facultad

2. Recomendaciones para mejorar los procesos

3. Pensamiento integrativo (Maestría)

\section{LA PREGUNTA ES CÓMO NUTRIRLA}

- Problema no es la definición - Se agota rápido.

\section{DISENNO CENTRADO EN EL USUARIO \\ DESIGN THINKING \\ DISEÑO ESTRATÉGICO}

PREGRADO

1. Comprensión estructura económica y académica.

2. ¿Cuáles son los aspectos no considerados?

3. Cambio de estructura-Textos práctica integrada

4. Contextualización - Marco teórico

Todo lo que se ha hecho en concurrencia y cómo llevarlo al diseño

Y

Elementos científicos de la construcción llevados a la docencia.

INNOVACIÓN Y CREATIVIDAD
- Problema planteado

- Metodología propuesta

- Resultado con el estudiante
A Figura 3. Diseño

concurrente en el taller

de diseño

Fuente: los autores. totalidad de los requerimientos establecidos, etc. Asimismo, se reducen las duplicidades porque con el esquema de coordinación se presenta la complementariedad y se reducen los tiempos ante problemas de proyecto, todo ello en una comunidad de la comunicación en arquitectura, es decir, donde se suministra toda la información que se tenga a la mano para que todo el mundo haga uso de esa información y ese conocimiento se disponga en beneficio de los procesos de aprendizaje.

\section{CONCLUSIONES}

Se ha afirmado que el diseño concurrente es un método de posible aplicación en el proyecto de arquitectura. Ello nos indica que la forma de hacer y afrontar los problemas de proyecto puede tener cierta similitud con su aplicación en la industria. Estas transformaciones en la estructura de pensamiento han facilitado el cambio en los procesos para la implementación del modelo.
Para la implementación del diseño concurrente en el desarrollo del proyecto de arquitectura, se deben cumplir las siguientes condiciones. Primero, es necesario un cambio de pensamiento que pasa inicialmente por una etapa previa de pensamiento lineal al pensamiento integrativo. Segundo, del pensamiento integrativo se pasa al simultáneo o concurrente, donde surgen nuevos conceptos, porque no se trata de decir lo mismo de otra manera, y se dan transformaciones trascendentales como cambiar lo pragmático por lo operativo y lo objetual por lo relacional (espacio, tiempo, cultura).

El diseño concurrente se ha establecido como una metodología que busca la eficiencia del proceso de formación mediante la sincronización de los campos del conocimiento disciplinar, con una orientación fuerte hacia lo interdisciplinar y fortaleciendo el pensamiento simultáneo, mediante la eficacia en el uso de los recursos y la integración de competencias teóricas y prácticas. 
Se trata de una sincronización (representada por el proyecto de arquitectura construido) orientada en dos sentidos: en el primero incorpora los componentes básicos y disciplinares de cada uno de los campos del saber, y en el segundo establece un lazo con las búsquedas, inquietudes y la construcción de problemas singulares que cada individuo como vinculador principal de la información establece de acuerdo con sus inquietudes.

Como estrategia pedagógica, el diseño concurrente permite a los profesionales propiciar la autonomía y anticiparse a los problemas al involucrarse en el campo de las nuevas metodologías aplicadas a la resolución de preguntas, lo que implica la interacción de los líderes de estudio por cada nivel, así como la utilización de nuevos programas y la ayuda de software especializado hacia el desarrollo total del proyecto que, de alguna manera, le permita a los actores descubrir nuevas respuesta a las preguntas planteadas o formular nuevas situaciones e interrogantes.

\section{REFERENCIAS}

Arango, S. M., Serna, U. C. A. y Gómez, B. A. C. (2012). Inferencia difusa aplicada a la ingeniería concurrente para el diseño de productos de manufactura en condiciones de incertidumbre. Revista Ingenierías de la Universidad de Medellín, 11 (21), 127-137. Recuperado de: http://www.redalyc.org/ articulo.oa? $\mathrm{id}=75025842011$.

Badr L. y Salah M. (1993). Automation support for concurrent software engineering. Monterrey: Calhoun, Institutional Archive of the Naval Postgraduate School. Recuperado de: http://hdl.handle.net/10945/28688

Barba, E. (2000). Ingeniería concurrente: guía para su implantación en la empresa. Diagnóstico y evaluación. Barcelona: Ediciones Gestión. Recuperado de: http://books. google.es/books?id=4vcly5AsFl8C\&printse $\mathrm{C}=$ frontcover \&dq = Ingenieria + concurrent $\mathrm{e} \& \mathrm{hl}=\mathrm{es} \& \mathrm{sa}=\mathrm{X} \& \mathrm{ei}=\mathrm{x} 1 \mathrm{p} 6$ UsegBsSrhQfZt HIBg\&ved=0CCQQ6AEwAA

Carretero, M. C., Contero, M., Valiente J. y Gómis, J. M. (2002). Metodologías de diseño para la industria textil y cerámica, basadas en el concepto de ingeniería concurrente. Documento presentado en el XIV Congreso Internacional de Ingeniería Gráfica, Universidad Politécnica de Valencia. Recuperado de: http://www.revistavirtualpro.com/biblioteca/ metodologias-de-diseno-para-la-industriatextil-y-ceramica-basadas-en-el-conceptode-ingenieria-concurrente

Corominas, J. y Pascual, J. A. (eds.) (1996). Diccionario crítico etimológico castellano e hispánico. Madrid: Gredos.

Correal, G. D. (2007). El proyecto de arquitectura como forma de introducción de conocimiento: la investigación proyectual. Revista de Arquitectura, (9), 48-58. Recuperado de: http://www.redalyc.org/articulo. oa?id=125112650010

Correal, G. D. (2010). Bitácora: un recorrido por el proyecto arquitectónico. Bogotá: Universidad Católica de Colombia.

Cuervo, R. J. (1994). Diccionario de Construcción y Régimen de la Lengua Castellana. Bogotá: Instituto Caro y Cuervo.

Escorsa C. P. y Valls P. J. (2005). Tecnología e Innovación en la Empresa (2 ed.). Barcelona: Alfaomega Ediciones, Universidad Politécnica de Cataluña.

Forero La Rotta, L. A. y Flórez Millán, L. A. (2005). Estado del arte del Concepto de Diseño Urbano. Revista Arquitectura, (7), 39-41.
García, F. R. (2004). Ingeniería concurrente y tecnologías de la información. Revista Ingenierías de la Universidad de Medellín, 3 (22), 40. Recuperado de: http://ingenierias.uanl.mx/22/ingenieriaconcu.PDF

Jiang, T. (2000). Conflict cause identification in web-based concurrent engineering design system (Disertación doctoral como requisito para el grado de doctor en Filosofía). Universidad de la Florida. Recuperado de: https://archive.org/details/conflictcauseide00jian

Londoño, F. G. (1994). Ingeniería concurrente: hacia un desarrollo integrado de productos y servicios. Perspectivas tecnológicas para la competitividad. Revista Universidad EAFIT, 30 (96), 8. Recuperado de http://publicaciones.eafit.edu.co/index.php/revista-universidad-eafit/article/download/1378/1249.

Lu, G. y Kaxiras, E. (2004). An overview of multiscale simulations of materials, department of physics and division of engineering and applied science. Cambridge: Departamento de física y división de ingeniería y ciencias aplicadas, Harvard University. Recuperado de: arXiv:cond-mat/0401073

Luna Amaya, C. (1999). Ingeniería simultánea: un enfoque para reducir los tiempos de entrega, mejorar la calidad y disminuir los costos. Revista Ingeniería y Desarrollo. 5, 81. Recuperado de: http://rcientificas. uninorte.edu.co/index.php/ingenieria/article/viewFile/2211/1433

Luna Amaya, C. y Mendoza Bayuelo, A. C. (2004). Metodología para mejorar la ingeniería de producto/proceso basado en la ingeniería concurrente. Revista Ingeniería y Desarrollo. 16, 60. Recuperado de: http:// rcientificas.uninorte.edu.co/index.php/ ingenieria/article/viewFile/2345/1530

Maturana, H. (1995). La realidad: ¿Objetiva o Construida? I. Fundamentos biológicos de la realidad. México: Anthropos.

Mayne, T. (2005). 1. Change of Perish, Report on Integrated Practice. New York: The American Institute of Architecture. (Remarks on building information modeling at the 2005 AIA convention, Las Vegas, EE.UU.)

Moliner, M. (ed.) (1982). Diccionario del uso de español (tomo A-G, p. 71). Madrid: Gredos.

Quiroga Parra, D. y Hernández Arias, B. H. (2009). Desarrollo tecnológico e innovación de productos y procesos en las empresas: análisis empírico de un modelo de inno- vación basado en la gestión del conocimiento y las TIC. Encuentro de investigadores en prospectiva, innovación y gestión del conocimiento, Universidad del Valle. Santiago de Cali, octubre de 2009. p. 122. Recuperado de: http://administracion.univalle.edu.co/ Comunidad/Memorias/evento6/archivos/ viii. $\% 20$ desarrollo $\% 20$ tecnologico $\% 20$ e\%20innovacion.pdf

Real Academia Española (RAE) (2001). Diccionario de la Lengua Española (22 ed.). Madrid: Espasa Calpe.

RHEA Group (2011). Concurrent design. Recuperado de: http://www.rheagroup.com/ space-systems-engineering/concurrentdesign-engineering/

Rodríguez Luna, M. E. (1998). El diálogo como fundamento de la relación interdisciplinaria: las teorías. En Rueda, J. E. y González M. (eds.). Urdimbres y tramas en la investigación interdisciplinaria: Los Hilos (pp.19-31). Bogotá: Magisterio, Colección Aula Abierta.

Rossi, A. (1977). Introducción a Boullé: para una arquitectura de tendencia. Barcelona: Gustavo Gili.

Simons \& Schuster (eds.) (1973). International Dictionary English/Spanish Spanish/English. New York: Simon \& Schuster Macmillan Company.

Universidad Católica de Chile - DuocUC (2002). Aplicación del diseño concurrente en la PYME chilena. Santiago de Chile: Centro de Diseño y Desarrollo Integrado (DuocUC-CDDI), Proyecto FDI C699 - TC02. Recuperado de: http://www.duoc.cl/edd/?p=801

Universidad Católica de Colombia (2010). Proyecto Educativo del Programa de Arquitectura. Bogotá: Universidad Católica de Colombia.

Winner, R. I., Pennell, J. P., Bertrand, H. E., Slusarczuk, M. G. (1988). The role of concurrent engineering in weapon system acquisition. Institute for Defense Analisys (IDA) Report R-338, December, p. 11. Recuperado de: ADA203615 


\section{(A) CON RESPECTO A LOS AUTORES}

Para la Revista de Arquitectura, la postulación de un artículo indica que el o los autores certifican que conocen y aceptan la política editorial, para lo cual firmarán en original y remitirán el formato RevArq FP00 Carta de originalidad.

Para efectos de la autoría y coautoría de artículos se diferencian dos tipos "obra en colaboración" y "obra colectiva". La primera es aquella cuya autoría corresponde a todos los participantes al ser fruto de su trabajo conjunto. En este caso, se requiere el consentimiento de todos ellos para su divulgación. La obra colectiva es en la que, aunque participan diversos colaboradores, hay un autor que toma la iniciativa, la coordinación y realización de dicha obra. En estos casos, la autoría correspondería a dicha persona (salvo pacto en contrario) y sería suficiente únicamente con su autorización de divulgación.

En virtud de mantener el equilibro de las secciones y las mismas oportunidades para todos participantes, un mismo autor puede postular dos o mas artículos de manera simultanea, y previa evaluación de pares, la publicación se hará en volúmenes diferentes.

Se recomienda que el número de autores por artículo no sea superior a cinco integrantes y el orden en que se enuncien corresponda a los aportes de cada uno a la construcción del texto. Si se incluyen más personas se siguiere que sea en calidad de colaboradores o como parte de los agradecimientos. La Revista de Arquitectura respetará el orden en que figuren en el original remitido. La comunicación se establece con uno de los autores, quien a su vez será el responsable de informar a los demás colaboradores.

Una vez publicado el artículo, se envía al autor la versión impresa y digital, las cuales puede distribuir de manera libre respetando la licencia de acceso abierto y la integridad de la Revista de Arquitectura.

Para el caso del autoarchivo, si hay una versión previa (working paper - 'literatura gris' o pre-print) o una versión posterior (revisada o mejorada o post-print), el autor está en libertad de publicarlas en un sitio web o repositorios, siempre haciendo referencia a la publicación realizada en la Revista de Arquitectura.

\section{(A) ACCESO ABIERTO}

La Revista de Arquitectura, en su misión de divulgar la investigación y apoyar el conocimiento y discusión en las campos de interés, proporciona acceso libre, inmediato e irrestricto a su contenido de manera gratuita mediante la distribución de ejemplares impresos y digitales. Los interesados pueden leer, descargar, guardar, copiar y distribuir, imprimir, usar, buscar o referenciar el texto completo de los artículos o de la totalidad de la Revista de Arquitectura

Esta revista se acoge una licencia Creative Commons (CC) de Atribución - No comercial - Compartir igual, 4.0 Internacional: "E material creado puede ser distribuido, copiado y exhibido por terceros si se muestra en los créditos. No se puede obtener ningún beneficio comercial y las obras derivadas tienen que estar bajo los mismos términos de licencia que el trabajo original".

(i)(2) Para más información: http://

BY NO SA Co.creativecommons.org/tipos-de-licencias/

Las licencias CC se basan en el principio de la libertad creativa con fines académicos, científicos, culturales. Las licencias CC complementan el derecho de autor sin oponerse a este.

La Revista de Arquitectura es divulgada en centros y grupos de investigación, en bibliotecas y universidades y en las principales facultades de arquitectura, mediante suscripción anual o canje, este último se formaliza mediante el formato RevArq FP20 Canjes

Para aumentar su visibilidad e impacto de los artículos, se envían a bases de datos y sistemas de indexación y resumen (SIR) y asimismo pueden ser consultados y descargados en la página web de la revista.

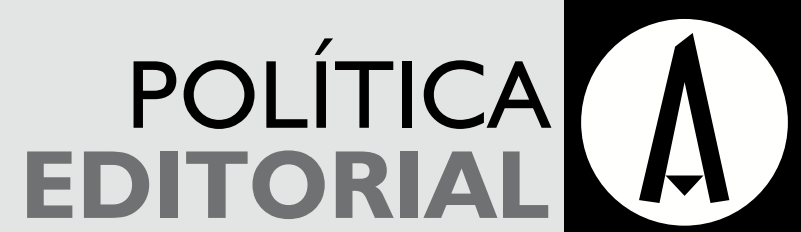

APRINCIPIOS ÉTICOS Y BUENAS PRÁCTICAS

La Revista de Arquitectura no tiene tarifa por procesamiento de artículos ni costos asociados al valor de página publicada.

Los artículos publicados en la Revista de Arquitectura son sometidos al cumplimiento de los principios éticos contenidos en las diferentes declaraciones y legislaciones sobre propiedad intelectual y derechos de autor específicos del país donde se realizó la investigación. En consecuencia, los autores de los artículos aceptados para publicar y que presentan resultados de investigaciones, deben firmar la declaración de originalidad, de cesión de derechos y de cumplimiento total de los principios éticos y las legislaciones específicas.

La Revista de Arquitectura se guía por las normas internacionales sobre propiedad intelectual y derechos de autor, y de manera particular el artículo 58 de la Constitución Política de Colombia, la Ley 23 de 1982 y el Acuerdo 172 del 30 de Septiembre de 2010 (Reglamento de propiedad intelectual de la UNIVERSIDAD CATÓLICA DE COLOMBIA).

Los autores, el editor, los miembros de los comités y los pares deben seguir las normas éticas internacionales (http://publicationethics.org) con el fin de evitar casos de fabricación, falsificación, omisión de datos y plagio.

La fabricación de resultados se ocasiona al mostrar datos inventados por los autores; la falsificación resulta cuando los datos son manipulados y cambiados a capricho de los autores; la omisión se origina cuando los autores ocultan deliberadamente un hecho o dato, y el plagio cuando un autor presenta como ideas propias, datos creados por otros. Los casos de plagio son los siguientes: copia directa de un texto sin entrecomillar o citar la fuente, modificación de algunas palabras del texto, paráfrasis y falta de agradecimientos. La revista se apoya en herramientas que detectan cualquiera de estos casos en los artículos postulados.

Una vez constatadas la Revista de Arquitectura podrá hacer públicas las malas prácticas científicas como plagio, falsificación o invención de datos, apropiación individual de autoría colectiva y publicación duplicada por parte del autor o los autores. El autor quedará impedido para postular artículos por dos años.

\section{A MANEJO DE LA INFORMACIÓN Y PRIVACIDAD}

HABEAS DATA

Para dar cumplimiento a lo previsto en el artículo 10 del Decreto 1377 de 2013, reglamentario de la Ley 1581 de 2012 y según el Acuerdo 002 del 4 de septiembre de 2013 de la UNIVERSIDAD CATÓLICA DE COLOMBIA, "por el cual se aprueba el manual de políticas de tratamiento de datos personales"

La UNIVERSIDAD CATÓLICA DE COLOMBIA, considerada como responsable y/o encargada del tratamiento de datos personales, manifiesta que los datos personales de los autores, integrantes de los comités y pares evaluadores, se encuentran incluidos en nuestras bases de datos; por lo anterior y en cumplimiento de las disposiciones legales vigentes, la Universidad solicitará siempre su autorización, para que en desarrollo de sus funciones propias como Institución de Educación Superior, en especial las relacionadas con la docencia, la extensión y la investigación, la UNIVERSIDAD CATÓLICA DE COLOMBIA pueda recolectar, recaudar, almacenar, usar, circular, suprimir, procesar, intercambiar, compilar, dar tratamiento, actualizar, transmitir y/o transferir a terceros países y disponer de los datos que le ha suministrado y que han sido incorporados en las bases de datos de todo tipo que reposan en la Universidad.

La UNIVERSIDAD CATÓLICA DE COLOMBIA queda autorizada, de manera expresa e inequívoca, en los términos señalados por el Decreto 1377 de 2013, para mantener y manejar la información de nuestros colaboradores (autores, integrantes de los diferentes comités y pares evaluadores), así mismo los colaboradores podrán ejercer sus derechos a conocer, actualizar, rectificar y suprimir sus datos personales, para lo cual se han dispuesto las siguientes cuentas de correo electrónico:

contacto@ucatolica.edu.co y revistadearquitectura@ucatolica.edu.co 
La Revista de Arquitectura. recibe de manera permanente artículos y los periodos de publicación son enero-diciembre de cada año. A medida que se van artículos recibiendo artículos se procesan.

El idioma principal es el español y como opcionales están definidos el inglés y el portugués; los textos pueden ser escritos y presentados en cualquiera de estos idiomas.

Los artículos postulados deben corresponder a las categorías universalmente aceptadas como producto de investigación, ser originales e inéditos y sus contenidos responder a criterios de precisión, claridad y brevedad.

Como punto de referencia se pueden tomar las tipologías y definiciones del Índice Bibliográfico Nacional, Publindex, para los artículos tipo 1,2 y 3 que se describen la continuación:

1) Artículo de investigación científica y tecnológica: documento que presenta, de manera detallada, los resultados originales de proyectos terminados de investigación. La estructura generalmente utilizada contiene cuatro apartes importantes: introducción, metodología, resultados y conclusiones.

\section{A INSTRUCCIONES PARA POSTULAR ARTÍCULOS}

Presentar el artículo mediante comunicación escrita dirigida al Editor de la Revista de Arquitectura (RevArq FP00 Carta de originalidad) ${ }^{1}$, en soporte digital debidamente firmada y una copia impresa (si es local o escaneada), adjuntando hoja de vida del autor (diligenciar el formato RevArq FP01 Hoja de Vida). En la comunicación escrita el autor debe expresar, que conoce y acepta la política editorial de la Revista de Arquitectura, que el artículo no está postulado para publicación simultáneamente en otra revistas u órganos editoriales y que -de ser aceptado- cede todos los derechos de reproducción y distribución del artículo a la UNIVERSIDAD CATÓLICA DE COLOMBIA Como editora de la revista.

Los artículos deben tener en cuenta las siguientes recomendaciones:

- En la primera página del documento se debe incluir

Título: en español e inglés y no exceder 15 palabras.

SUBтítulo: opcional, complementa el título o indica las principales subdivisiones del texto.

DATOS DEL AUTOR O AUTORES: nombres y apellidos completos, filiación institucional ( $\mathrm{Si}$ el artículo tiene patrocinio, financiación o apoyo de una institución o entidad). Como nota al pie (máximo 150 palabras): formación académica, experiencia profesional e investigativa, vinculación laboral, premios o reconocimientos, publicaciones representativas e información de contacto correo electrónico, dirección postal o numero telefónico.

DESCRIPCIÓN DEL PROYECTO DE INVESTIGACIÓN: en la introducción describir el tipo de artículo y brevemente el marco investigativo del cual es resultado y diligenciar el formato (RevArq FP02 Info Proyectos de Investigación)

RESUMEN:debe ser analítico, se redacta en un solo párrafo, da cuenta del tema, el objetivo, la metodología, los puntos centrales y las conclusiones, no debe exceder las 150 palabras y se presenta en españo e inglés (Abstract)

Palabras Clave: cinco palabras o grupo de palabras, ordenadas alfabéticamente y que no se encuentren en el título o subtítulo, deben presentarse en español e inglés (Key words), estas sirven para clasifica temáticamente al artículo. Se recomienda emplear principalmente palabras definidas en el tesauro de la Unesco http://databases.unesco.org thessp/ o en el tesauro de Arte \& Arquitectura (C) www.aatespanol.cl

- La segunda página y siguientes deben tener en cuenta estas recomendaciones:

El cuerpo del artículo generalmente se divide en: Introducción, Metodología, Desarrollo, Resultados y Discusión, y finalmente Conclusiones, luego se presentan las Referencias bibliográficas, Tablas, Leyendas de las Figuras y Anexos.

TexTO: Todas las páginas deben venir numeradas y con el título de artículo en la parte inferior (pie de página). Márgenes de $3 \mathrm{~cm}$ por todos los lados, interlineado doble, fuente, Arial o Times New Roman de 12 puntos, texto justificado. La extensión de los artículos debe estar alrededor de 5.000 palabras ( \pm 20 páginas, incluyendo gráficos, tablas, etc.); como mínimo 3.500 y máximo 9.000 palabras. Se debe seguir el estilo vigente y recomendado en el Manual para Publicación de la Asociación Americana de Psicología (APA). (Para mayor información http://www.apastyle.org).

CITAS Y NOTAS AL PIE: las notas aclaratorias o notas al pie no deben exceder cinco líneas o 40 palabras, de lo contrario estas deben ser incorporadas al texto general. Las citas pueden ser:

Corta (con menos de 40 palabras) se incorporan al texto y pueden ser: textuales (se encierran entre dobles comillas), parafraseo o resumen (se escriben en palabras del autor dentro del texto).

Cita textual extensa (mayor de 40 palabras) debe ser dispuesta en un renglón y un bloque independiente con sangrías y omitiendo las comillas, no olvidar en ningún caso la referencia del autor (Apellido, año, p. 00).

REFERENCIAS: como modelo para la construcción de referencias se emplea el siguiente:
2) Artículo de reflexión: documento que presenta resultados de investigación terminada desde una perspectiva analítica, interpretativa o crítica del autor, sobre un tema específico, recurriendo fuentes originales.

3) Artículo de revisión: documento resultado de una investigación terminada donde se analizan, sistematizan e integran los resultados de investigaciones publicadas o no publicadas, sobre un campo en ciencia o tecnología, con el fin de dar cuenta de los avances y las tendencias de desarrollo. Se caracteriza por presentar una cuidadosa revisión bibliográfica de por lo menos 50 referencias.

También se pueden presentar otro tipo de documentos diferentes a los anteriormente descritos como pueden ser: artículo corto, reporte de caso, revisión de tema, documento resultado de la revisión crítica de la literatura sobre un tema en particular, cartas al editor, traducción, documento de reflex ión no derivado de investigación, reseña bibliográfica así como proyectos de arquitectura o urbanismo, entre otros.
Libro

Autor-Apellidos-, A.A.-Nombres- (año de la publicación). Título de la obra. (Edición). Ciudad, País: Editorial.

Capítulo de un libro

Autor, A.A., \& Autor, B.B. (Año de la publicación). Título del capítulo. En A.A. Editor \& B.B. Editor (eds.), Título del libro (páginas del capítulo). Ciudad: Editorial.

\section{Publicación seriada (Revista)}

Autor, A.A., Autor, B.B., \& Autor, C.C. (Año de la publicación, incluya el mes y día de la publicación para publicaciones diarias, semanales o mensuales). Título del artículo. Título de la revista, diario, semanario, Volumen, (número), páginas.

Leyes, decretos, resoluciones, etc.

ey, decreto, resolución, etc, número (Año de la publicación, incluya el mes y día de la publicación). Título de la ley, decreto, resolución etc. Título de la publicación oficialmente. Ciudad, País

Artículo que se encuentra en una revista publicada en Internet Autor, A.A. \& Autor, B.B. (año, si se encuentra). Título del artículo. Título de la revista, volumen, (número). Recuperado de URL.

Siglas: en el caso de emplear siglas en el texto, cuadros, gráficos y/o fotografías, se deben proporcionar las equivalencias completas de cada una de ellas la primera vez que se empleen y encerrarlas entre corchetes [ ]. En el caso de citar personajes reconocidos se deben colocar nombres y/o apellidos completos, nunca emplear abreviaturas.

GRÁFICOS Y TABLAS: las figuras (gráficos, diagramas, ilustraciones, planos, mapas o fotografías) y las tablas deben contener número, título o leyenda explicativa relacionada con el tema del artículo que no exceda las 15 palabras (Figura 01 xxxxx, Tabla 01 xxxx, etc.) y la procedencia (autor $y / 0$ fuente, año, p. 00). Estos se deben incluir en el texto $y$ se deben citar de forma directa o entre paréntesis; se recomienda hacerlo mediante referencias cruzadas.

También se deben entregar en medio digital independiente del texto en formatos editables o abiertos. La numeración debe corresponder a la posición en el texto y según la extensión del artículo se deben incluir de 5 a 10 gráficos

El autor es el responsable de adquirir los derechos y/o las autorizaciones de reproducción a que haya lugar, para imágenes y/o gráficos tomados de otras fuentes, así como de entrevistas o material generado por colaboradores diferentes a los autores.

Fotografía: pueden ser entregadas en original para ser digitalizadas, de lo contrario se deben digitalizar con una resolución igual o superior a 300 dpi para imágenes a color y 600 para escala de grises. Los formatos de las imágenes pueden ser TIFF, PSD o JPG y deben cumplir con características expresadas en el punto anterior (gráficos)

Planimetría: se debe entregar la planimetría original en medio digital en lo posible en formato CAD y sus respectivos archivos de plumas o en PDF, de no ser posible se deben hacer impresiones en tamaño carta con las referencias de los espacios mediante numeración y lista adjunta. Deben tener escala gráfica, escala numérica, norte, coordenadas y localización. En lo posible no se deben textos, achurados o tramas.

Para más detalles, consultar el documento RevArq Parámetros para Autores Descripción en el portal web de la Revista de Arquitectura (www.ucatolica.edu.co).

\section{BENEFICIOS}

Como reconocimiento a los autores, se les hará envío postal de tres (3) ejemplares de la edición impresa sin ningún costo y entregada en la dirección consignada en el formato de hoja de vida (RevArq FP01) adicionalmente se les enviará el vínculo para la descarga de la versión digital. También se enviará una constancia informativa en la que se relaciona la publicación del artículo y de manera opcional se puede detallar las fechas del proceso editorial y el arbitraje realizado. 
La selección de pares evaluadores se realiza de acuerdo a los siguientes criterios:

- Afinidad temática

- Formación académica

- Experiencia investigativa y profesional

- Producción editorial en revistas similares y/o en libros resultado de investigación.

El proceso de arbitraje se basa en los principios de equidad e imparcialidad y en los criterios de calidad y pertinencia.

El desarrollo de la evaluación se realiza según el formato RevArq FP10 Evaluación de artículos calidad y las observaciones que el par considere necesarias en el cuerpo del artículo. En cualquiera de los conceptos que emita el par (aceptar, aceptar con modificaciones o rechazar) y como parte de la labor formativa y de comunidad académica, el par expondrá sugerencias para mejorar el documento. El par evaluador podrá solicitar una nueva relectura del artículo después de los ajustes realizados por el autor.

El par también deberá diligenciar el formato RevArq FP01 Hoja de Vida, con el fin de certificar y soportar el proceso de evaluación ante los SIR que así lo soliciten.

En el proceso de arbitraje se emplea el método doble ciego, los nombres de evaluador no serán conocidos por el autor y viceversa. Con el fin de garantizar el anonimato del autor, al artículo postulado se le han podido suprimir nombres, instituciones y/o imágenes que puedan ser asociadas de manera directa al autor.

Aunque se procura el anonimato, una vez recibida la invitación a evaluar el articulo, el par debe cerciorarse que no exista conflicto de intereses o alguna limitante que afecte la evaluación o que pueda ser vista como tal, (lazos familiares, amistad o enemistad, vínculos contractuales o laborales, posiciones éticas, etc), de presentarse esta situación se notificara al editor

Dada la confidencialidad del proceso de evaluación y considerando los derechos autor y de propiedad intelectual que pueda haber sobre el material que se entrega, el evaluador se compromete a mantener en absoluta reserva su labor, a limitar el uso de la obra entregada solo para el propósito de evaluación y a devolver la documentación que se le remite una vez realizada la evaluación.

El tiempo establecido para las evaluaciones es de máximo un (1) mes a partir de la confirmación de la recepción de la documentación. Ese plazo podrá ser modificado de mutuo acuerdo entre el editor y el par, siempre cuando no afecte la periodicidad de la revista, la impresión y/o el tiempo para emitir una respuesta al autor.

\section{BENEFICIOS}

Como retribución a los pares evaluadores, se les hará envío postal de un (1) ejemplar de la edición impresa sin ningún costo y entregada en la dirección consignada en el formato de hoja de vida. También si es de interés para el par, podrá hacer la solicitud de alguna de las publicaciones editadas y presentes en el catálogo de publicaciones de la UNIVERSIDAD CATÓLICA DE COLOMBIA, previa aprobación de la Editorial y sujeto a la disponibilidad.

Si lo desea tendrá derecho a solicitar una constancia de la colaboración en la evaluación de artículos, la cual solo contendrá el periodo en el cual se realizó la evaluación. También tendrá la posibilidad de aceptar o no la publicación de su nombre, nacionalidad y nivel máximo de formación en la página web de la Revista de Arquitectura en su calidad de colaborador.
El Comité Editorial de la Revista de Arquitectura es la instancia que decide la aceptación de los artículos postulados, el editor selecciona y clasifica solo los artículos que cumplan con los requisitos establecidos en las instrucciones para los autores.

Todos los artículos se someterán a un primer dictamen del Comité Editorial, el editor y de los editores de sección, teniendo en cuenta:

- Afinidad temática, relevancia del tema y correspondencia con las secciones definidas.

- Respaldo investigativo.

En caso de que los artículos requieran ajustes preliminares, este será devuelto al autor antes de ser remitidos a pares. En este caso el autor tendrá 15 días para remitir nuevamente el texto con los ajustes solicitados.

Después de la preselección se asignan mínimo dos pares evaluadores internos $y / 0$ externos especializados quienes emitirán su concepto utilizando el formato RevArq FP10 Evaluación de artículos calidad, se garantiza la confidencialidad y anonimato de autores y árbitros (modalidad doble ciego).

Del proceso de arbitraje se emite uno de los siguientes conceptos que son reportados al autor:

- (AA) Aceptar el artículo sin observaciones

- (AM) Aceptar el artículo con modificaciones: se podrá sugerir la forma más adecuada para una nueva presentación y se adjuntará la síntesis de los conceptos emitidos por los pares, el autor puede o no aceptar las observaciones según sus argumentos. Si las acepta, cuenta con quince (15) días para realizar los ajustes pertinentes.

- (RA) Rechazar el artículo: en este caso se entregará al autor un comunicado exponiendo las razones por las cuales se rechaza. En este caso, el autor puede volver a postular el artículo e iniciar nuevamente el proceso de arbitraje, siempre y cuando se evidencien los ajustes correspondientes.

En el caso de presentarse diferencias sustanciales y contradictorias en los conceptos de evaluación, el editor remitirá el artículo a un evaluador más o un miembro del Comité Editorial podrá asumir la tarea de actuar como el tercer árbitro, esto con el fin de tomar una decisión sobre la publicación del artículo.

El Comité Editorial se reserva el derecho de aceptar o no la publicación del material recibido. También se reserva el derecho de sugerir modificaciones de forma, ajustar las palabras clave o el resumen y de someterlo a corrección de estilo.

Cuando un artículo es aceptado para su publicación, los derechos de reproducción y divulgación son de la UNIVERSIDAD CATÓLICA DE COLOMBIA, lo cual se formaliza mediante la firma de la autorización de reproducción RevArq FP03 Autorización reproducción artículo. Esta autorización de uso no es exclusiva

\section{NOTAS ACLARATORIAS}

Aunque la recepción del material se notificará por correo electrónico en un plazo máximo de (8) ocho días, los procesos de evaluación, arbitraje, edición y publicación pueden tener un plazo máximo de (12) doce meses. A petición del autor, el editor informará sobre el estado del proceso editorial del artículo.

El editor de la Revista de Arquitectura es el encargado de establecer contacto entre los autores, árbitros, evaluadores y correctores, ya que estos procesos se realizan de manera anónima.

La Revista de Arquitectura publica un número limitado de artículos por volumen y busca el equilibrio entre las secciones, motivo por el cual aunque un artículo sea aceptado podrá quedar aplazado para ser publicado en una próxima edición, en este caso el autor estará en la posibilidad de retirar la postulación del artículo o de incluirlo en el banco de artículos del próximo volumen.

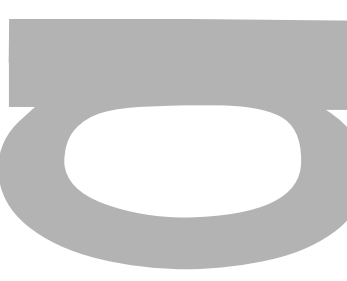

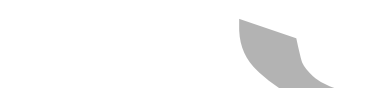
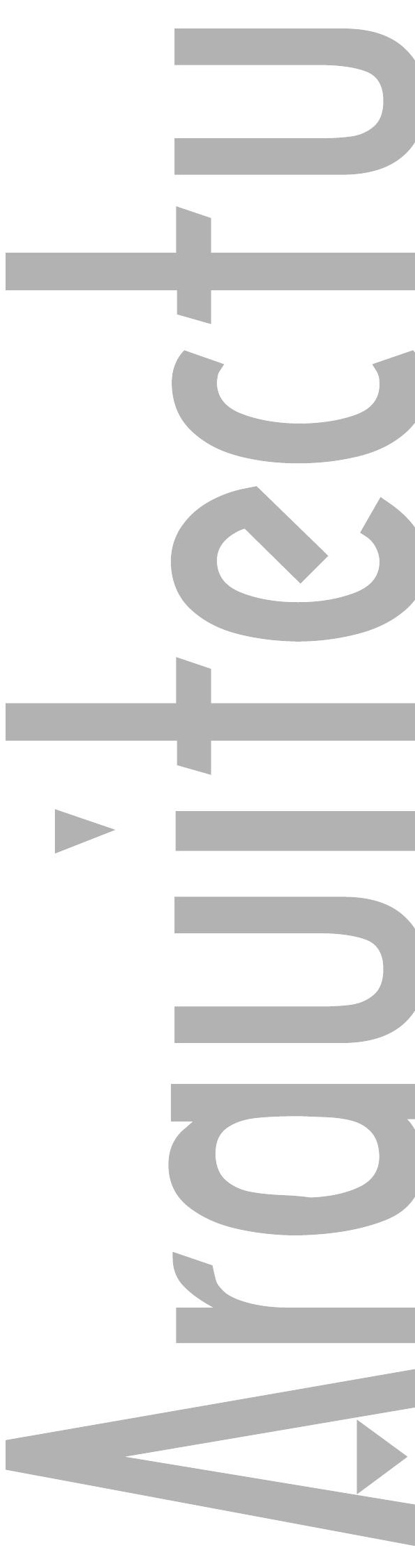
LOS USOS Y LA APROPIACIÓN DEL ESPACIO PÚBLICO PARA

EL FORTALECIMIENTO DE LA DEMOCRACIA

USES AND SPACE APPROPRIATION OF PUBLIC SPACE FOR THE

DEMOCRACY BUILD-UPABSTRACT

Pablo PÁramo, AndRea Milena Burbano

CIUDAD Y COMPROMISO CIUDADANO EN

LA HISTORIA DE OCCIDENTE

نे

CITY AND CITIZEN COMMITMENT IN WESTERN HISTORY

CARACTERIZACIÓN DEL MODELO DE APRENDIZAJE A

PARTIR DE LABORATORIOS DE DISEÑO CON ÉNFASIS EN

FACTORES SOCIALES

CHARACTERIZATION OF THE LEARNING MODEL BASED ON DESIGN

LABORATORIES WITH AN EMPHASIS ON SOCIAL FACTORS

\section{ÁLVARO JAVIER BOLAÑOS PALACIOS,}

ANÁLISIS URBANO Y FORMAL DEL EDIFICIO MIGUEL DE

AGUINAGA

URBAN AND FORMAL ANALYSIS OF MIGUEL DE AGUINAGA BUILDING

FELIPEVILLA MONTOYA, LEONARDO CORREA VELASQUEZ

VIVIENDAS DE EMERGENCIA EN URUGUAY

EMERGENCY HOUSING IN URUGUAY

JuAN José Fontana CABEZAS, PABlo Gustavo LaURino

CASTIGLIONI, MARIA VIRGINIA VILA RIVERO, LETICIA ANDREA BOTTI

AZAMBUYY

CUESTIONES DE MÉTODO CREATIVO

METAMORFOSIS Y CONCIENCIA MATERIAL EN LOS

PROCESOS CREATIVOS EN ARQUITECTURA

CREATIVE METHOD MATTERS

MetAMORPHOSIS AND MATERIAL CONSCIOUSNESS IN THE CREATIVE PROCESSES IN ARCHITECTURE

CARLOS IVÁN RUEDA PLATA

CRÍTICA SISTÉMICA

UN ENFOQUE HERMENÉUTICO DEL FENÓMENO ARQUITECTÓNICO

SYSTEMIC CRITICISM - AN HERMENEUTICAL STANDPOINT OF THE

ARCHITECTURAL PHENOMENON

ESKA ELENA SOLANO MENESES

TRADUCCIÓN DEL DISEÑO CONCURRENTE AL PROYECTO DE ARQUITECTURA

TRANSLATION OF THE CONCURRENT DESIGN TO THE

ARCHITECTURE PROJECT

Luis Álvaro Flórez Millán, Jairo Hernan OVALLE Garay,

LEONEL AUGUSTO FORERO LA ROTTA

EFICIENCIA DE ESTRATEGIAS DE ENFRIAMIENTO

PASIVO EN CLIMA CÁLIDO SECO

EFFICIENCY OF PASSIVE COOLING STRATEGIES IN HOT DRY WEATHER

LUIS CARLos HerRERA SOSA

SIMULACIONES AMBIENTALES PARA LA SELECCIÓN DE MATERIALES EN DISEÑO DE ALOJAMIENTOS TEMPORALES EN CLIMAS TROPICALES

ENVIRONMENTAL SIMULATIONS FOR MATERIAL SELECTION

IN TEMPORARY HOUSING DESIGN IN TROPICAL WEATHER

CONDITIONS

$$
\text { SARA LUCIANI M. }
$$

A INFLUÊNCIA DAS PRATELEIRAS DE LUZ NO

APROVEITAMENTO DA LUZ NATURAL SOB OBSTRUÇÃO EXTERNA

THE INFLUENCE OF LIGHT SHELVES IN THE HIGH-PERFORMANCE

USE OF NATURAL LIGHT UNDER EXTERNAL OBSTRUCTION

RICARDO NACARI MAIOLI, MARIANI DAN TAUFNER,

CRISTINA ENGEL DEALVAREZ

LA HABITABILIDAD COMO VARIABLE DE DISEÑO DE

$\pm \quad$ EDIFICACIONES ORIENTADAS A LA SOSTENIBILIDAD

$=$ Habitability AS DESIGN VARIABle OF BuILDINGS HEADING

Uं TOWARDS SUSTAINABILITY

¿ ROLANDO ARTURO CUBILLOS GONZÁLEZ, JOHANNA TRUJILLC,

Oscar AlFonso Cortés CELy, Claudia Milena Rodrígueż

ÁlVAREZ, MAYERLY ROSA VILLAR LOZANO

LA SOSTENIBILIDAD DE LA VIVIENDA TRADICIONAL:

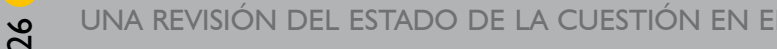
ㄴ MUNDO

U TRADITIONAL Housing SUSTAINABILITY: A REVIEW OF THE STAT ¿ OF THE ART IN THE WORLD

RIGOBERTO LÁRRAGA LARA, MIGUEL AGUILAR ROBLEDO,

\section{HIFHA \\ ( $5^{\circ}$ CONCURSO DE DISEÑO EN ACERO PARA ESTUDIAN-}

m TES DE ARQUITECTURA EN COLOMBIA - 2014

ن் SEGUNDO PUESTO. MEMORIA

a 5TH STEEL DESIGN ARCHITECTURE STUDENT COMPETITION IN COLOMBIA -20I4

\section{DIEGO ALEJANDRO MORA CASAS, JUAN CAMILO RI}
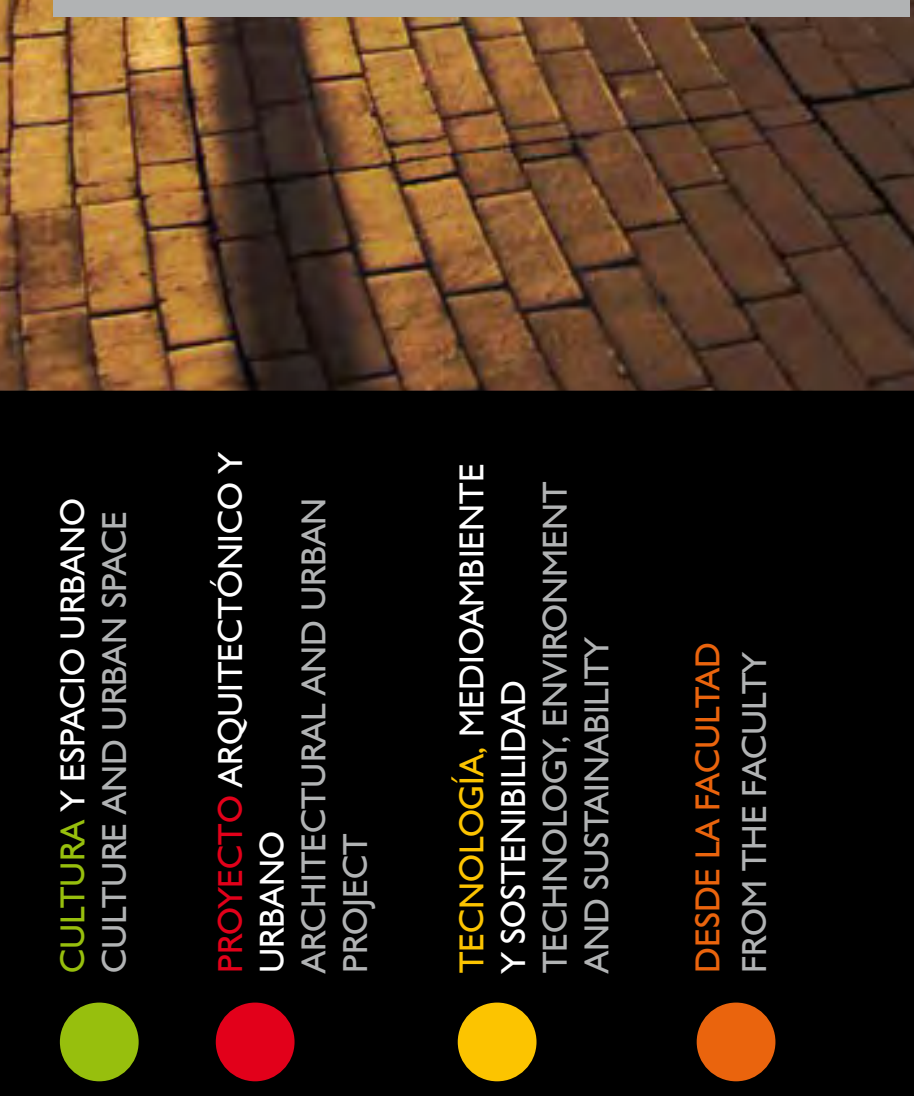

La Revista de Arquitectura es arbitrada e indexada y está presente en:

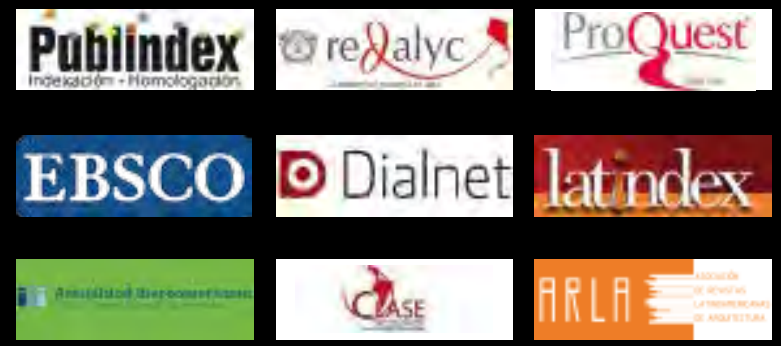

f

REVISTA DE ARQUITECTURA - UNIVERSIDAD CATOLICA DE COLOMBIA
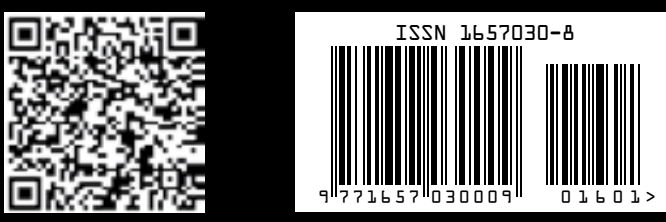